\title{
Regulation of the NLRP3 inflammasome and macrophage pyroptosis by the p38 MAPK signaling pathway in a mouse model of acute lung injury
}

\author{
DANDAN LI ${ }^{1}$, WEIYING REN ${ }^{2}$, ZHILONG JIANG ${ }^{1}$ and LEI ZHU ${ }^{1}$ \\ Departments of ${ }^{1}$ Pulmonary Medicine and ${ }^{2}$ Gerontology, Zhongshan Hospital, Fudan University, Shanghai 200032, P.R. China
}

Received February 23, 2018; Accepted July 25, 2018

DOI: $10.3892 / \mathrm{mmr} .2018 .9427$

\begin{abstract}
Acute lung injury and acute respiratory distress syndrome (ALI/ARDS) is characterized by uncontrolled progressive lung inflammation. Macrophages serve a key role in the pathogenesis of ALI/ARDS. Macrophage pyroptosis is a process of cell death releasing the proinflammatory cytokines interleukin (IL)-1 $\beta$ and IL-18. It was hypothesized that macrophage pyroptosis may partially account for the uncontrolled lung inflammation of ALI/ARDS. In the present study, greater macrophage pyroptosis in lipopolysaccharide (LPS)-treated macrophages and the ALI/ARDS mouse model was observed. The expression of nucleotide-binding domain, leucine-rich-containing family, pyrin domain-containing (NLRP) 3 and IL-1 $\beta$ and cleavage of caspase-1 were significantly elevated following LPS treatment accompanied by greater activation of p38 mitogen-activated protein kinase (MAPK) signaling in vitro and in vivo. However, blocking p38 MAPK signaling through the inhibitor SB203580 significantly suppressed the acute lung injury and excessive lung inflammation in vivo, consistent with the reduced expression of the NLRP 3 inflammasome and IL-1 $\beta$ and cleavage of caspase-1. Pretreatment of the rat NR8383 macrophage cell line with SB203580 significantly decreased the population of caspase-1+PI+ pyroptotic cells and expression of NLRP3/IL-1 $\beta$. However, a larger population of Annexin V+PI- apoptotic cells was observed following blocking of the p38 MAPK signaling pathway. The results indicated that blockage of p38 MAPK signaling pathway skewed macrophage cell death from proinflammatory pyroptosis towards non-inflammatory apoptosis. These effects may contribute to attenuated acute lung injury
\end{abstract}

Correspondence to: Dr Lei Zhu, Department of Pulmonary Medicine, Zhongshan Hospital, Fudan University, 180 Feng Lin Road, Shanghai 200032, P.R. China

E-mail: tfzhu@126.com

Key words: acute lung injury and acute respiratory distress syndrome, alveolar macrophages, p38 mitogen-activated protein kinase signaling pathway, pyroptosis, nucleotide-binding domain, leucine-rich-containing family, pyrin domain-containing-3 inflammasome and excessive inflammation in the SB203580-treated mice. The results may provide a novel therapeutic strategy for the treatment of uncontrolled lung inflammation in patients with ALI/ARDS.

\section{Introduction}

Acute lung injury/acute respiratory distress syndrome (ALI/ARDS) is an acute progressing hypoxemic respiratory failure characterized by acute diffuse alveolar damage, influx of neutrophils and protein-rich exudates in alveolar spaces (1). Each year in the United States there are 190,600 cases of acute lung injury, which are associated with 74,500 mortalities and 3.6 million hospital days (2). The underlying immunological mechanisms are still not well defined. The uncontrolled excessive lung inflammation may account for the high mortality rate. Patients usually receive supportive treatments with mechanical ventilation and immunosuppressants, but the therapeutics do not prolong the survival rate in patients and animal models $(3,4)$. Altered alveolar macrophage activation and cell death are considered a major player in the progression of the uncontrolled acute lung inflammation among patients with ALI/ARDS (5-7).

Macrophages are heterogeneous cell components and serve distinct roles in the different stages of diseases $(8,9)$. Following exposure to pathogens, macrophages are activated releasing a variety of cytokines and other mediators. At later stages of the disease, the activated macrophages undergo noninflammatory apoptosis and are finally cleared by monocytes, an important pathological process in inflammation resolution and tissue remodeling (5). However, it is clinically reported that a high percentage of patients with severe sepsis and ALI/ARDS fail to recover from the acute lung inflammation, accompanied by persistent existence of the uncontrolled lung edema and excessive host response to pathogens $(10,11)$. According to previous reports it was hypothesized that the uncontrolled lung inflammation may be caused by both insufficient clearance of dead cells and release of proinflammatory cytokines during immune cell death $(12,13)$. A previous study indicated that macrophages can undergo inflammatory programmed cell death, called pyroptosis, under certain pathological circumstances (12). The pyroptotic cells are identified as caspase- 1 and propidium iodide (PI)-double positive cells and are characterized by their release of a large amount of hallmark proteins such as active 
interleukin (IL)-1 $\beta$ and IL-18 (14). Prior to pyroptosis, the nucleotide-binding domain, leucine-rich-containing family, pyrin domain-containing-3 (NLRP3) protein is upregulated and forms a protein complex known as the NLRP3 inflammasome, with apoptosis-associated speck-like protein containing a caspase recruitment domain (ASC) and pro-caspase-1. Active caspase- 1 can stimulate IL-1 $\beta$ and IL-18, causing the release of these active cytokines from pyroptotic cells (15). ASC is an important component of the NLRP3 inflammasome and participates in NLRP3 inflammasome activation (16). It was reported that ASC deficiency caused a defect in NLRP3 inflammasome assembly and protected against liver ischemia/reperfusion damage in animal models through suppression of the caspase-1/IL-1 $\beta$ signaling pathway (17). Other studies also demonstrated that the NLRP3 inflammasome can be activated by neutrophil-derived extracellular histones and complement component 5a, ultimately causing excessive tissue inflammation $(18,19)$.

A body of evidence confirmed that p38 mitogen-activated protein kinase (MAPK) signaling pathway participates in the progression of ALI/ARDS (20,21). p38 MAPK regulates cell growth, proliferation, differentiation, migration, apoptosis and inflammation $(22,23)$. In animals with lipopolysaccharide (LPS)-induced acute lung injury, p38 MAPK expression is upregulated (21). However, there is limited information about the role of p38 signaling pathway in macrophage pyroptosis and uncontrolled lung inflammation in the ALI/ARDS mouse model. In the present study, two macrophage cell lines and an ALI/ARDS mouse model were treated with p38 MAPK inhibitor SB203580 to block p38 MAPK signaling pathway prior to LPS treatment. The present results revealed that blockage of p38 MAPK signaling pathway with SB203580 suppressed macrophage pyroptosis and LPS-induced acute lung injury through negative regulation of NLRP3 inflammasome activation.

\section{Materials and methods}

Cell culture and treatments. The murine macrophage cell lines, RAW264.7 and NR8383 cells (American Type Culture Collection, Manassas, VA, USA), were cultured in Roswell Park Memorial Institute (RPMI)-1640 and F-12K medium (Thermo Fisher Scientific, Inc., Waltham, MA, USA), respectively, and supplied with $10 \%$ fetal bovine serum, $2 \mu \mathrm{M}$ glutamine (Gibco; Thermo Fisher Scientific, Inc.), $100 \mathrm{U} / \mathrm{ml}$ penicillin and $100 \mu \mathrm{g} / \mathrm{ml}$ streptomycin. NR8383 cells were treated with $1 \mu \mathrm{g} / \mathrm{ml}$ LPS (Sigma-Aldrich; Merck KGaA, Darmstadt, Germany) for $4 \mathrm{~h}$ at $37^{\circ} \mathrm{C}$, with or without pretreatment of 10 mM MAPK p38 inhibitor SB203580 (Selleck Chemicals, Houston, TX, USA) for $1 \mathrm{~h}$ at $37^{\circ} \mathrm{C}$. Conditioned media and cells were collected for measurement of protein expression levels by enzyme-linked immunosorbent assay (ELISA), reverse transcription-quantitative polymerase chain reaction (RT-qPCR) and western blot analysis.

Animal procedure. A total of 48 10-week-old male wild-type C57BL/6 mice were purchased from Shanghai Model Organisms Center, Inc. (Shanghai, China). All mice were housed at $22^{\circ} \mathrm{C}$ with 12 -h light/dark cycle and free access to food and water. The animal protocol was approved by the
Laboratory Animal Care and Use Committee at the Medical College of Fudan University, Zhongshan Hospital. Mice were intratracheally treated with $5 \mathrm{mg} / \mathrm{kg}$ LPS with or without $1 \mathrm{~h}$ intraperitoneal (i.p.) pretreatment with $20 \mathrm{mg} / \mathrm{kg}$ p38 MAPK inhibitor SB203580 (LPS group and SB203580/LPS group) at room temperature. Mice received PBS, and the same doses of SB203580 were used as controls (PBS and SB203580 groups). Following $24 \mathrm{~h}$ LPS/PBS treatment, collection of bronchoalveolar lavage fluid (BAL) was performed by intratracheal injection of $0.5 \mathrm{ml}$ of PBS followed by gentle aspiration. The lavage was repeated three times and the recovery rate was $>90 \%$. The collected BAL fluid was centrifuged at $400 \mathrm{x}$ g for $5 \mathrm{~min}$ at $4^{\circ} \mathrm{C}$ and cell pellets were suspended in $1 \mathrm{ml}$ of PBS and cell count was manually measured with a hemocytometer by light microscopy. The supernatant of BAL fluid was used for cytokine assay and the lung tissues were collected for further analysis.

Preparation of SB203580. SB203580 was purchased from Selleck Chemicals, dissolved with DMSO (Sigma-Aldrich, Merck KGaA) according to the manufacturer's protocol and diluted with PBS as a working solution. A final concentration of $2 \%$ DMSO was introduced in the cell culture media for each group, and 10\% DMSO in solution was used for administration into the mouse model. There were no signs of cell toxicity and mouse mortality with the concentrations used in vitro and in vivo (data not shown).

Wet/dry weight ratio. The wet and dry weights (W) of the left lung tissues were measured prior to and following drying at $65^{\circ} \mathrm{C}$ for $48 \mathrm{~h}$. Water content was obtained by calculating the $\mathrm{W} / \mathrm{D}$ weight ratio.

Lung histology. Lung tissue was fixed in $4 \%$ paraformaldehyde and sections of $5 \mu \mathrm{m}$ thickness were placed onto glass slides and stained with hematoxylin and eosin (Beyotime Institute of Biotechnology, Shanghai, China), according to the manufacturer's protocol, for histopathological examination. The lung histology was viewed under a light photomicroscope and evaluated for pathological changes using a double-blind method. The severity of lung injury was evaluated using a semiquantitative histological index, including alveolar edema, hemorrhage, alveolar septal thickening and infiltration of polymorphonuclear leukocytes. Each item was divided into four grades from 0 to 3 ( 0 , normal; 1 , mild; 2 , moderate; 3 , severe) and then calculated for a total acute lung injury score (24).

Western blot analysis. The collected cells $\left(1 \times 10^{6}\right.$ cells $\left./ \mathrm{ml}\right)$ were incubated with $100 \mu \mathrm{l}$ radioimmunoprecipitation assay lysis buffer (Beyotime Institute of Biotechnology) supplied with proteinase inhibitor phenylmethylsulphonyl fluoride (Beyotime Institute of Biotechnology) for $30 \mathrm{~min}$ on ice. The proteins of the lung tissues were extracted using a Nuclear and Cytoplasmic Protein Extraction kit (Beyotime Institute of Biotechnology) according to the manufacturer's protocol. Protein concentration was determined by bicinchoninic assay protein assay kit (Beyotime Institute of Biotechnology). Each $20 \mu \mathrm{g}$ protein sample was resolved on a $10 \%$ SDS-PAGE gel. The protein was transferred onto polyvinylidene fluoride membrane blots (Merck Millipore; Merck KGaA), and 
the blots were incubated with blocking buffer (Shanghai Beyotime Institute of Biotechnology) for $1 \mathrm{~h}$ at room temperature, followed by incubation with the indicated primary antibodies against NLRP3 (1:1,000; NBP2-12446; Novus Biologicals, LLC, Littleton, CO, USA), caspase-1 (1:1,000; Ab1872; Abcam, Cambridge, MA, USA), caspase-3 (1:1,000; 9665s; Cell Signaling Technology, Inc., Danvers, MA, USA) cleaved-caspase-3 (1:1,000; 9664s; Cell Signaling Technology, Inc.), Toll-like receptor (TLR)2 (1:1,000; ab108998; Abcam), TLR4 (1:1,000; sc-293072; Santa Cruz Biotechnology, Inc., Dallas, TX, USA), nuclear factor (NF)-кB p65 (1:1,000; 3033p; Cell Signaling Technology, Inc.), p-p38 (1:1,000; 4511S; Cell Signaling Technology, Inc.) and MAPK p38 (1:1,000; 4511S; Cell Signaling Technology, Inc) at $4^{\circ} \mathrm{C}$ overnight. The antibody anti-mouse $\beta$-actin (1:1,000; BM0627; Boster Biological technology, Pleasanton, CA, USA) was used for internal loading control and blots were incubated with stripping buffer at $37^{\circ} \mathrm{C}$ for $15 \mathrm{~min}$. The membranes were incubated with horseradish peroxidase-conjugated secondary antibodies (1:1,000; anti-rabbit:A0208; anti-mouse A0216; Beyotime Institute of Biotechnology) for $1 \mathrm{~h}$ at room temperature. Immune reactivity was visualized using an enhanced chemiluminescent reagent (Beyotime Institute of Biotechnology). Band intensity was quantitatively analyzed by densitometric analysis on ImageJ software version 1.37 (National Institutes of Health, Bethesda, MD, USA).

$R T$ - $q P C R$. cDNA was synthesized from $1 \mu \mathrm{g}$ total RNA with a ReverTra Ace qPCR RT Master Mix kit (Toyobo Life Science, Osaka, Japan). RT-qPCR was performed using SYBR-Green PCR Master Mix-Plus (Toyobo Life Science, Osaka, Japan). All the primers were synthesized by Shanghai BioSune Biotechnology Co. Ltd. Primer sequences are listed in Table I. qPCR reaction was performed on a 7500 Real-Time PCR system (Applied Biosystems; Thermo Fisher Scientific, Inc.) under the condition of $95^{\circ} \mathrm{C} 1 \mathrm{~min}$ followed by 40 cycles of $95^{\circ} \mathrm{C} 15 \mathrm{sec}, 60^{\circ} \mathrm{C} 60 \mathrm{sec}, 72^{\circ} \mathrm{C} 45 \mathrm{sec}$. The expression level was quantified using the $2^{-\Delta \Delta \mathrm{Cq}}$ method (25), relative to the internal control $\beta$-actin.

ELISA assay for cytokines. IL-1 $\beta$, tumor necrosis factor (TNF)- $\alpha$ and IL-6 expression levels in the BAL fluid or the supernatant of treated cells were measured by ELISA assays (IL-1 $\beta$ : Mouse: MLB00C, rat: RLB00; TNF- $\alpha$ : Mouse: MTA00B; IL-6: Mouse: M6000B, rat: R6000B; R\&D Systems Inc, Minneapolis, MN, USA) according to the manufacturer's protocols.

Immunofluorescence staining. RAW264.7 ( $1 \times 10^{4}$ cells $\left./ \mathrm{ml}\right)$ were stimulated with $1 \mu \mathrm{g} / \mathrm{ml}$ LPS for 4, 8, 12 and $24 \mathrm{~h}$. Following treatment, the cells were incubated with fixing buffer and were blocked with blocking buffer (Shanghai Beyotime Institute of Biotechnology) for $30 \mathrm{~min}$ at room temperature. Subsequently, the cells were incubated with primary antibodies against rabbit anti-NLRP3 (1:1,000; NBP2-12446; Novus Biologicals, LLC) and mouse anti-caspase-1 (1:1,000; sc-514; Santa Cruz Biotechnology, Inc.) for $2 \mathrm{~h}$ at $4^{\circ} \mathrm{C}$. The cells were incubated with secondary antibodies Cy3-conjugated anti-rabbit IgG (1:1,000; A0516; Shanghai Beyotime Institute of Biotechnology) and FITC-conjugated anti-mouse IgG (1:1,000; A0568;
Table I. Primers used for detection of gene expression.

\begin{tabular}{|c|c|}
\hline Genes & Primer sequences $\left(5^{\prime}-3^{\prime}\right)$ \\
\hline \multirow[t]{2}{*}{ Mouse-IL-1 $\beta$} & Forward AGAGCTTCAGGCAGGCAGTA \\
\hline & Reverse AGGTGCTCATGTCCTCATCC \\
\hline \multirow[t]{2}{*}{ Mouse-TNF- $\alpha$} & Forward ACGGCATGGATCTCAAAGAC \\
\hline & Reverse GTGGGTGAGGAGCACGTAGT \\
\hline \multirow[t]{2}{*}{ Mouse-IL-6 } & Forward CCAGTTGCCTTCTTGGGACT \\
\hline & Reverse GGTCTGTTGGGAGTGGTATCC \\
\hline \multirow[t]{3}{*}{ Mouse- $\beta$-actin } & Forward GTGCTATGTTGCTCTAGACTT \\
\hline & $\mathrm{CG}$ \\
\hline & Reverse ATGCCACAGGATTCCATACC \\
\hline \multirow[t]{2}{*}{ Rat-IL-1 $\beta$} & Forward AAAAATGCCTCGTGCTGTCT \\
\hline & Reverse TCGTTGCTTGTCTCTCCTTG \\
\hline \multirow[t]{2}{*}{ Rat-IL-6 } & Forward AGTTGCCTTCTTGGGACTGA \\
\hline & Reverse ACTGGTCTGTTGTGGGTGGT \\
\hline \multirow[t]{2}{*}{ Rat- $\beta$-actin } & Forward TGTCACCAACTGGGACGATA \\
\hline & Reverse GGGGTGTTGAAGGTCTCAAA \\
\hline
\end{tabular}

IL, interleukin; TNF, tumor necrosis factor.

Shanghai Beyotime Institute of Biotechnology) for $1 \mathrm{~h}$ at room temperature following incubation with the primary antibody and washing. DAPI was used for staining nuclei for $10 \mathrm{~min}$ at room temperature. Finally, the stained cells were visualized under a fluorescence microscope (Olympus Corporation, Tokyo, Japan).

Flow cytometry analysis. Pyroptotic cells were characterized by greater expression of cleaved caspase-1 and positive propidium iodide (PI) staining (26) and early apoptotic cells were Annexin V+PI- (27). Detection of apoptotic and pyroptotic cells by flow cytometry was performed with Annexin V: FITC Apoptosis Detection kit I (556547; BD Pharmingen; BD Biosciences, San Jose, CA, USA) and FLICA 660-YVAD-FMK far-red caspase-1 reagent (9122; ImmunoChemistry Technologies, LLC, Bloomington, MN, USA) according to the manufacturer's protocols in vitro (BD Pharmingen; BD Biosciences). Briefly, the cells $\left(1 \times 10^{5}\right.$ cells $\left./ \mathrm{ml}\right)$ were resuspended in $100 \mu \mathrm{l} 1 \mathrm{X}$ binding buffer and incubated with $5 \mu \mathrm{l}$ FITC-Annexin V (FL1 channel) and $5 \mu 1$ PI in the dark for $20 \mathrm{~min}$ at room temperature. The stained cells were washed with PBS twice and fixed in $4 \%$ paraformaldehyde. To analyze pyroptotic cells, a $150 \mu \mathrm{l}$ single cell suspension was incubated with $5 \mu$ l FITC-conjugated Annexin V, $5 \mu 1$ PI (FL2 channel) and $5 \mu 1$ FLICA 660-YVAD-FMK far-red caspase-1 reagent (FL4 channel) in the dark at room temperature for $20 \mathrm{~min}$, then washed with PBS and fixed with $4 \%$ paraformaldehyde for $10 \mathrm{~min}$ at room temperature. Analysis was performed on a FACScan cytometer (Becton Dickinson; BD Biosciences), and data were analyzed with FlowJo software version 7.6 (FlowJo LLC, Ashland, OR, USA).

Statistical analysis. All experimental values were presented as the mean \pm standard error of the mean. Statistical comparison between two groups was performed by Student's t-test, and one-way analysis of variance followed by Bonferroni post hoc 


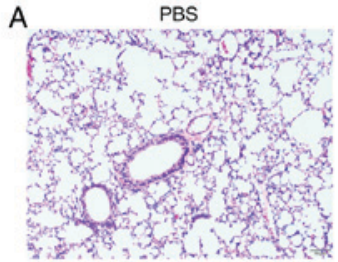

SB
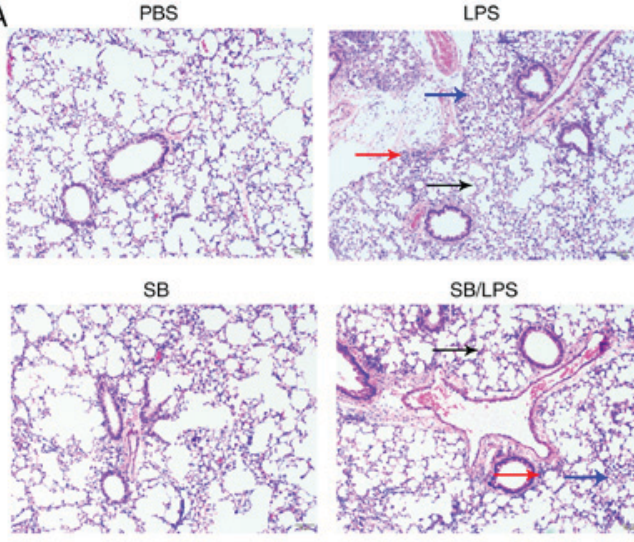

SB/LPS
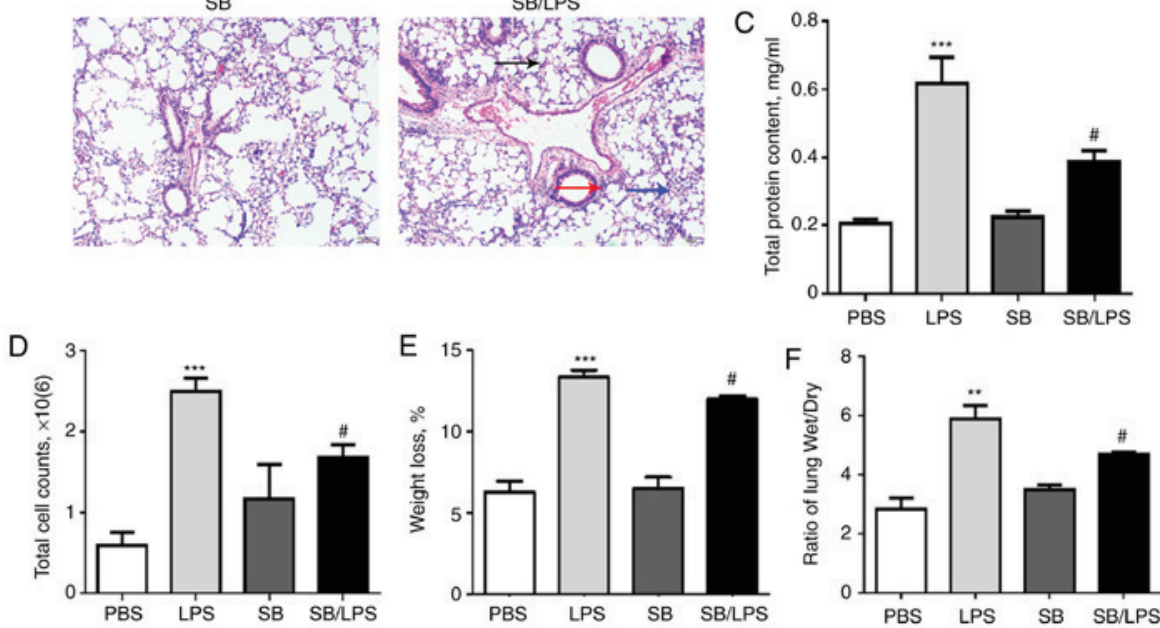

Figure 1. p38 MAPK inhibitor SB203580 suppresses acute lung injury and inflammation in mice after i.t. injection of LPS. All parameters were measured at $24 \mathrm{~h}$ following the i.t. LPS treatment. (A) Representative images of the histology of lung tissues by H\&E staining. Black arrows: Thickened alveolar septal; blue arrows: Alveolar hemorrhage and red arrows: infiltrated polymorphonuclear leukocytes (magnification, x200). (B) Lung pathological score in terms of lung injury and inflammation. (C) Total protein content and (D) total cell counts in BAL; (E) weight loss and (F) ratio of lung Wet/Dry were analyzed. Data are presented as the mean \pm standard error of the mean. ${ }^{* *} \mathrm{P}<0.01,{ }^{* * *} \mathrm{P}<0.001$ vs. PBS group; ${ }^{\#} \mathrm{P}<0.05,{ }^{\# \#} \mathrm{P}<0.01$ vs. LPS group, $\mathrm{n}=5$ per group. BAL, bronchoalveolar lavage fluid; i.t., intratracheal; LPS, lipopolysaccharide; MAPK, mitogen-activated protein kinase.

analyses was performed among multiple groups for parametric data. $\mathrm{P}<0.05$ was considered to indicate a statistically significant difference.

\section{Results}

Intraperitoneal injection of p38 MAPK inhibitor SB203580 suppresses murine acute lung injury and inflammation. To establish an acute lung injury mouse model, 8- to 10-week-old male mice were injected with $5 \mathrm{mg} / \mathrm{kg}$ LPS intratracheally (i.t.). The mice injected with PBS were used as controls. Massive inflammatory infiltrates, perivascular edema and severe alveolar space destruction were observed compared to the PBS-treated group $24 \mathrm{~h}$ following LPS injection (Fig. 1A). However, pretreatment with the p38 MAPK inhibitor SB203580 significantly reversed the severity of acute lung injury compared with the mice that received LPS treatment alone (Fig. 1A and B). Additionally, LPS treatment significantly induced more total BAL protein content (Fig. 1C) and cell counts (Fig. 1D). The weight loss (Fig. 1E) and lung wet/dry ratio (Fig. 1F) were also significantly elevated after i.t. LPS injection. The beneficial effects were consistent with the reduced total BAL protein content (Fig. 1C), cell counts (Fig. 1D), weight loss (Fig. 1E) and lung wet/dry ratio (Fig. 1F) in the group of mice that received both SB203580 and LPS.

Blockage of the p38 MAPK signaling pathway attenuates the expression of proinflammatory cytokines and the NLRP3 inflammasome in the inflamed murine lung tissues. To determine whether the reduced acute lung injury and inflammation in the SB203580-treated mice was supported by the decreased expression of proinflammatory cytokines, IL-1 $\beta$, tumor necrosis factor (TNF)- $\alpha$ and IL-6 expression levels in BAL and lung tissues were measured by ELISA and RT-qPCR analysis. Supporting the observation above, it was demonstrated that the expression levels of IL-1 $\beta$ (Fig. 2A and B), TNF- $\alpha$ (Fig. 2C and D) and IL-6 (Fig. 2E and F) were greatly elevated at the mRNA and protein levels in the mice treated with LPS. However, blockage of p38 MAPK signaling pathway by SB203580 pretreatment significantly attenuated their expression (Fig. 2).

IL-1 $\beta$ is a downstream proinflammatory cytokine of the NLRP3 inflammasome and caspase-1 activation (28). To further investigate the effects of p38 MAPK signaling pathway blockage on the NLRP3 inflammasome, the relative protein expression levels of NLRP3, pro-caspase-1, cleaved-caspase-1 (Fig. 3A) and TLR2 (Fig. 3B) was analyzed by western blot analysis and the mRNA of NLRP3 (Fig. 3C) and TLR2 (Fig. 3D) by RT-qPCR. SB203580 pretreatment significantly reversed the LPS-induced upregulation of NLRP3, cleaved caspase-1 and TLR2, indicating a beneficial role of blockage of the p38 MAPK signaling pathway in reducing the formation of the NLRP3 inflammasome and pyroptosis.

LPS treatment increases the expression of NLRP3 and caspase-1 in macrophages. To further confirm the effects of LPS in inducing macrophage pyroptosis, the mouse macrophage cell line, RAW264.7 cells were treated, with $1 \mu \mathrm{g} / \mathrm{ml}$ LPS for $4,8,12$, and $24 \mathrm{~h}$. The NLRP3 expression was analyzed by immunofluorescence staining. As a result, 
A

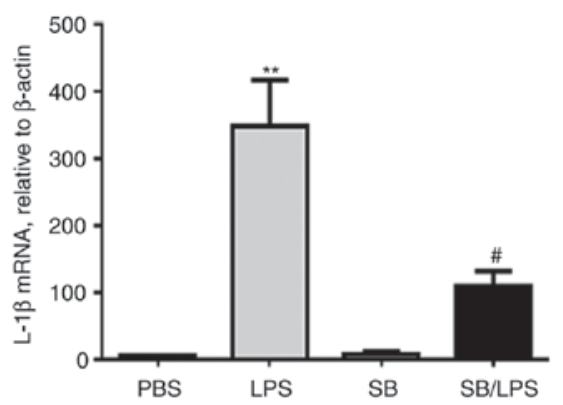

C

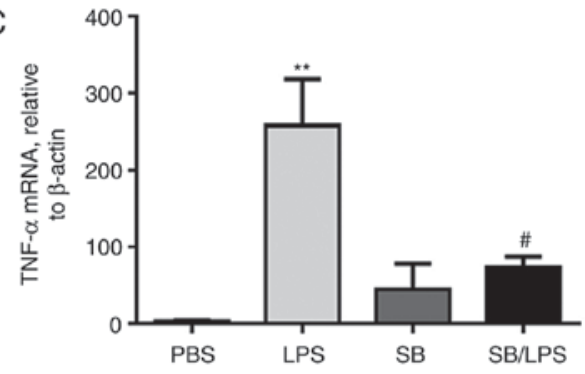

E

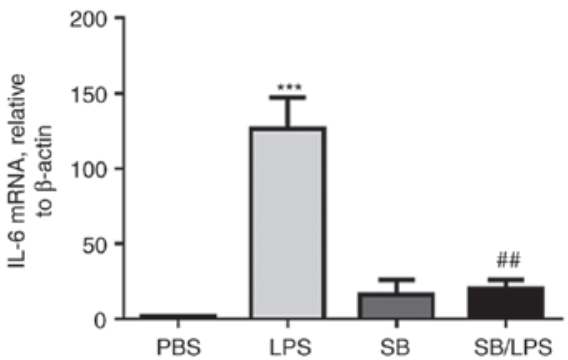

B

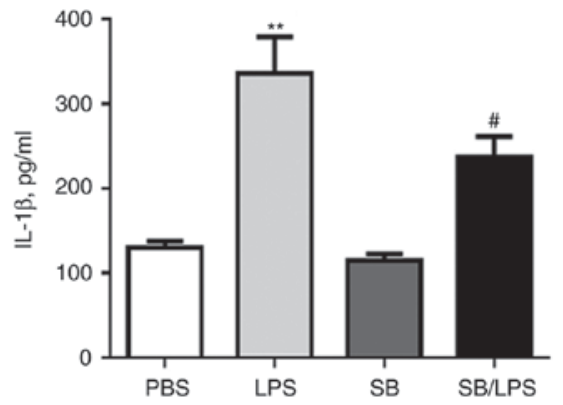

D

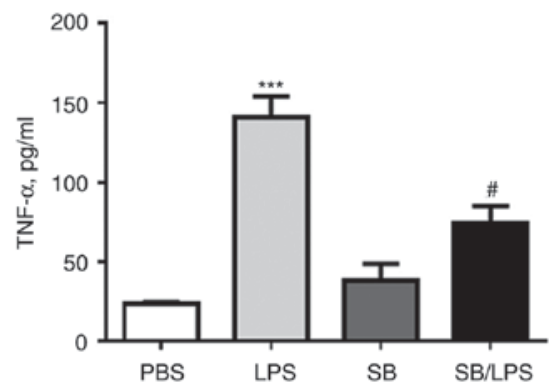

F

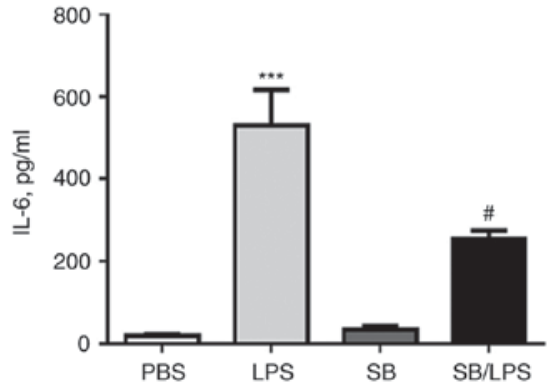

Figure 2. p38 MAPK inhibitor SB203580 suppresses IL-1 $\beta$, TNF- $\alpha$ and IL-6 expression in mice following the i.t. injection of LPS. Twenty-four hours following SB203580 i.p. and LPS i.t. treatment, the lung and BAL fluids were collected. IL-1 $\beta$ (A) mRNA and (B) protein expression levels; TNF- $\alpha$ (C) mRNA and (D) protein expression levels and IL-6 (E) mRNA and (F) protein expression levels were analyzed by RT-qPCR analysis and by ELISA analysis, respectively. Data are presented as the mean \pm standard error of the mean. ${ }^{* *} \mathrm{P}<0.01,{ }^{* * *} \mathrm{P}<0.001$ vs. PBS group; ${ }^{*} \mathrm{P}<0.05,{ }^{\# /} \mathrm{P}<0.01$ vs. LPS group, $\mathrm{n}=5$ mice per group. BAL, bronchoalveolar lavage fluid; i.p., intraperitoneal; i.t., intratracheal; IL, interleukin; LPS, lipopolysaccharide; TNF, tumor necrosis factor.
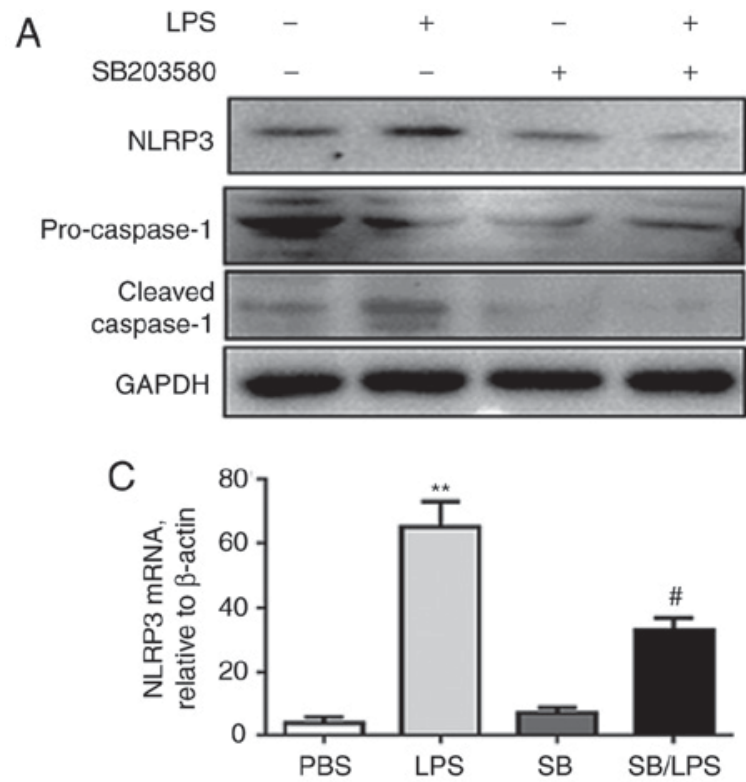
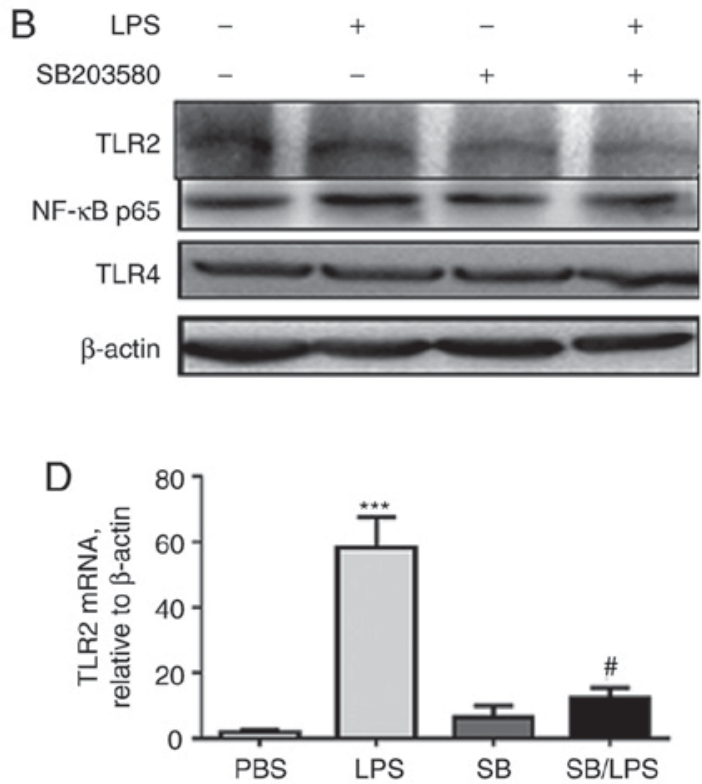

Figure 3. p38 MAPK inhibitor SB203580 suppresses caspase-1, NLRP3 and TLR2 expression in mice following i.t. injection of LPS. The pro-caspase-1, cleaved caspase-1, NLRP3 (A), NF-אB and TLR2 and TLR4 (B) were analyzed by western blot analysis following LPS treatment. NLRP3 (C) and TLR2 (D) mRNA expression levels were analyzed by RT-qPCR analysis. ${ }^{* *} \mathrm{P}<0.01,{ }^{* * *} \mathrm{P}<0.001$ vs. PBS group; ${ }^{*} \mathrm{P}<0.05$ vs. LPS group, $\mathrm{n}=5$ per group. IL, interleukin; i.t., intratracheal; LPS, lipopolysaccharide; MAPK, mitogen-activated protein kinase; NF- $\mathrm{KB}$, nuclear factor- $\mathrm{k}$-light-chain-enhancer of activated B cells; NLRP, nucleotide-binding domain, leucine-rich-containing family, pyrin domain-containing; TLR, Toll-like receptor. 
A

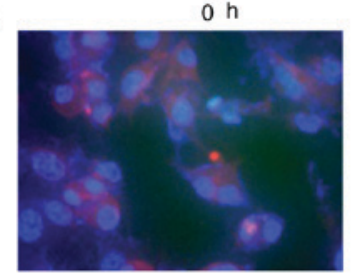

$12 \mathrm{~h}$

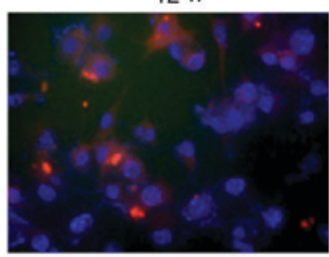

C
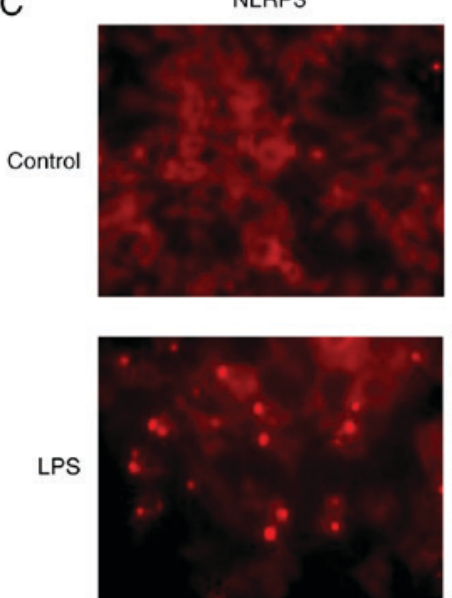

$4 \mathrm{~h}$

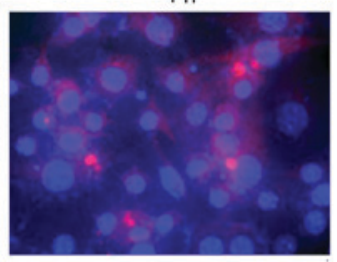

$24 \mathrm{~h}$

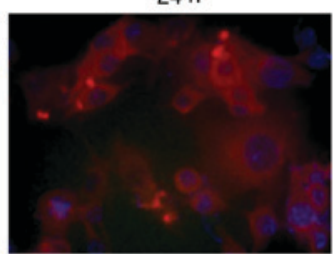

Cleaved caspase-1
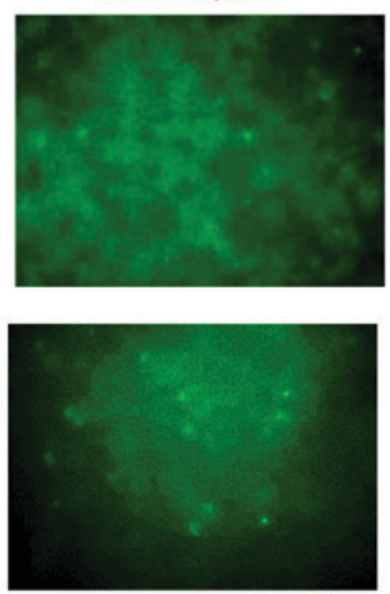

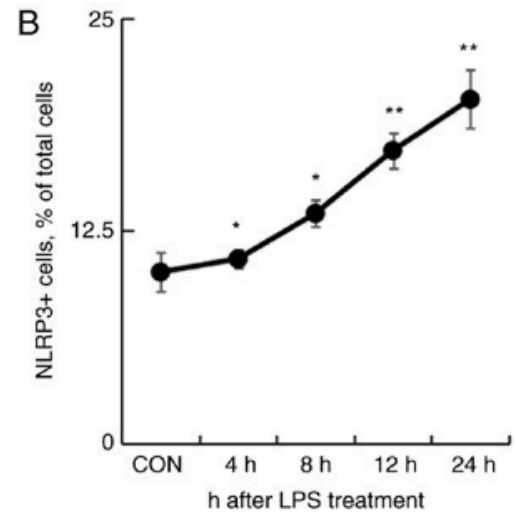

Merge
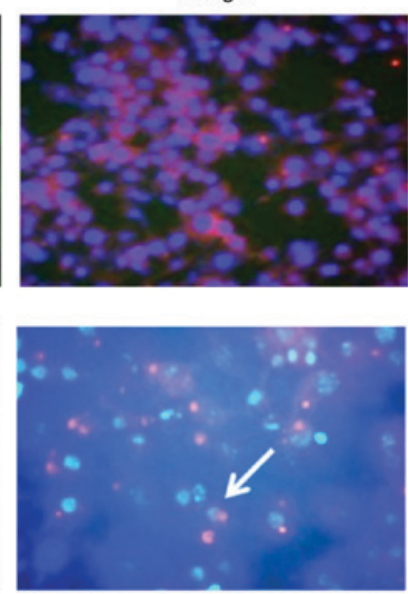

Figure 4. LPS treatment increases NLRP3 expression in macrophages in vitro in a time-dependent manner. RAW264.7 were treated with $1 \mu \mathrm{g} / \mathrm{ml}$ LPS for $4,8,12$, and $24 \mathrm{~h}$. The untreated cells were used as controls. The expression of NLRP3 protein was analyzed by immunofluorescence staining. (A) Representative image of NLRP3 expression levels in cells treated at different time points and (B) quantification of them following LPS treatment. Data are presented as a ratio of NLRP3+ cells to the number of nuclei in 7 random selected fields $n=5$ per group. ${ }^{*} \mathrm{P}<0.05,{ }^{* *} \mathrm{P}<0.01$ vs. untreated cells. (C) LPS treatment increases the formation of $\mathrm{NLRP} 3$ inflammasomes, and NLRP3 protein was colocalized with the cleaved caspase-1. Red: NLRP3; Green: Cleaved caspase-1; Blue: DAPI-stained nuclei. White arrow indicates NLRP3 inflammasome. LPS, lipopolysaccharide; NLRP, nucleotide-binding domain, leucine-rich-containing family, pyrin domain-containing.

the NLRP3-expressing cells were increased $4 \mathrm{~h}$ following LPS treatment that was gradually increased from $10.1 \pm 1.1 \%$ untreated cells to a maximal $20.2 \pm 1.7 \%$ cells treated for $24 \mathrm{~h}$ $(\mathrm{P}<0.01$; Fig. $4 \mathrm{~A}$ and $\mathrm{B})$. In addition, the increasing number of NLRP3+ and cleaved caspase-1+ cells was observed by immunofluorescence staining following LPS treatment, indicating a role of LPS in NLRP3 inflammasome formation and activation (Fig. 4C).

Blockage of p38 MAPK signaling pathway reverses the LPS-induced expression of NLRP3 and caspase-1 in macrophages. Pyroptosis and early apoptosis of NR8383 after treatment were determined by flow cytometry. Further analysis indicated that LPS treatment resulted in 1.7-fold increases in caspase-1+PI+ pyroptotic cells as well as Annexin V+PI- early apoptotic cells (Fig. 5A and B). The present analysis further indicated that pretreatment with SB203580 significantly reversed LPS-induced caspase-1+PI+ pyroptotic cells (Fig. 5A and C) but enhanced LPS-induced Annexin V+PI- apoptotic cells (Fig. 5B and D). Thus, SB203580 treatment reduced cell pyroptosis but increased cell apoptosis by blockage of the p38 MAPK signaling pathway. LPS induced uncontrolled lung inflammation, possibly by inducing more cell pyroptosis and less cell apoptosis through p38 MAPK signaling, but this needs to be investigated further.

Additional analysis by western blot revealed that the blockage of p38 MAPK signaling pathway suppressed LPS-induced p38 MAPK activation (Fig. 6A) and inhibited the LPS-induced upregulation of NLRP3 and TLR2 proteins (Fig. 6B), consistent with the results of pyroptosis analyzed by flow cytometry (Fig. 5). However, higher expression levels of cleaved caspase-3 were detected in the cells treated with both SB203580 and LPS (Fig. 6C), which was in line with the results analyzed by flow cytometry, demonstrating a larger Annexin V+PI- apoptotic cell population following SB203580 pretreatment (Fig. 5B and D).

Further analysis of cytokines in the supernatant and the cell lysate of the treated cells indicated that LPS treatment induced higher mRNA expression levels of IL-1 $\beta$ and IL-6 (Fig. 7A and B, respectively) and higher protein expression levels (Fig. 7C and D). However, the elevated expression of IL-1 $\beta$ and IL-6 were significantly suppressed by SB203580 pretreatment (Fig. 7; P<0.05), further supporting the effects of p38 MAPK blockage in reducing macrophage pyroptosis in vitro, but this needs to be validated further. 

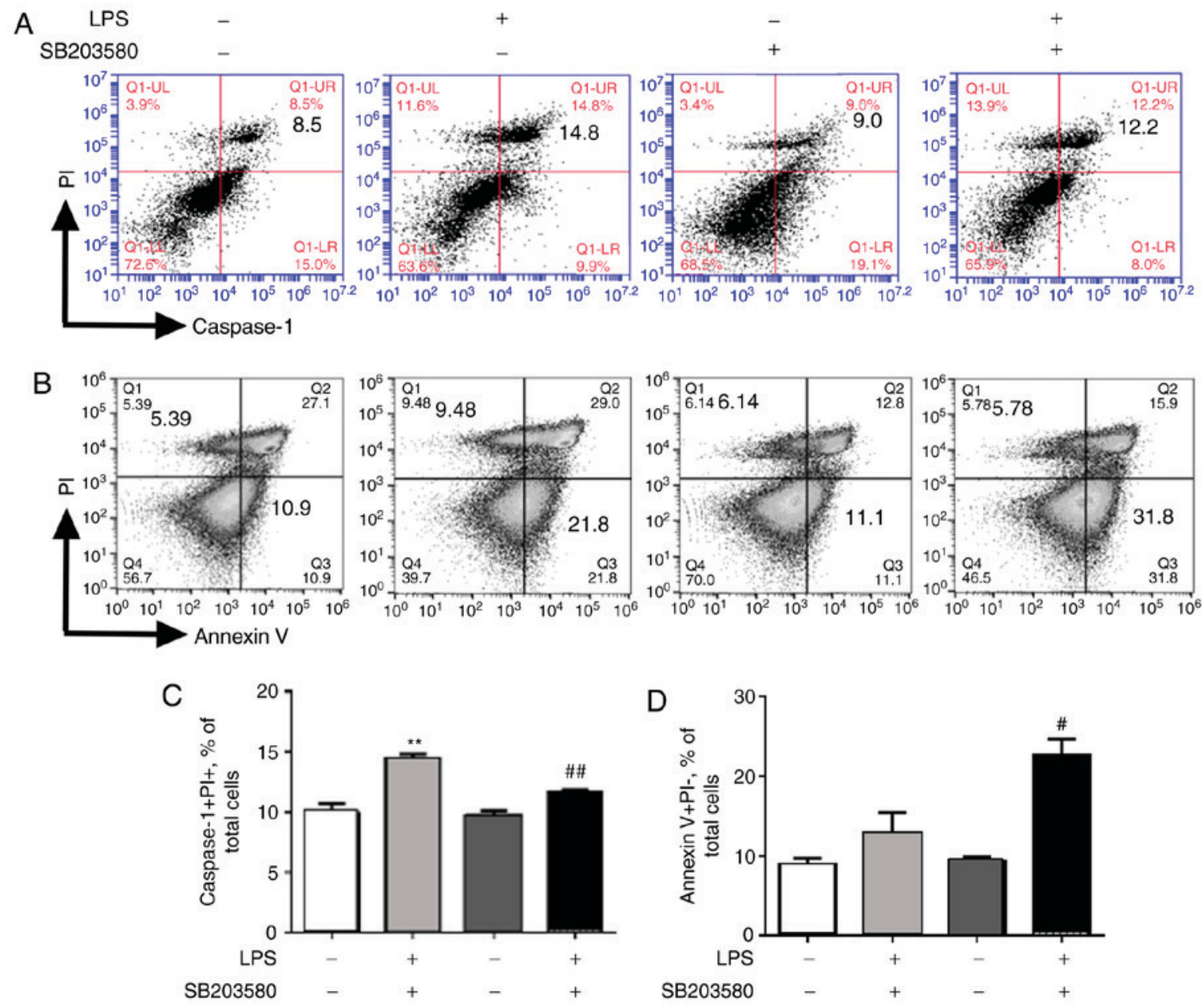

Figure 5. p38 MAPK inhibitor SB203580 suppresses caspase-1 expression but increased Annexin V+ cell population in vitro. The rat macrophage cell line NR8383 was treated with $1 \mu \mathrm{g} / \mathrm{ml}$ LPS for $4 \mathrm{~h}$ with/without pretreatment with $10 \mu \mathrm{M}$ SB203580. The caspase- 1 and Annexin V+cells were measured by flow cytometry. (A) LPS increased caspase-1 expression which was reversed by pretreatment with SB203580. (B) LPS increased Annexin V+PI- early apoptotic cells and pretreatment with p38 MAPK inhibitor SB203580 enhanced this. (C) Quantitative analysis of caspase-1+PI+ pyroptotic cells and of (D) Annexin V+PI- apoptotic cells. Data are presented as the mean \pm standard error of the mean. ${ }^{* *} \mathrm{P}<0.01$ vs. the untreated control group; ${ }^{\#} \mathrm{P}<0.05,{ }^{\#} \mathrm{P}<0.01$ vs. the LPS-treated group, $\mathrm{n}=3$ per group. LPS, lipopolysaccharide; MAPK, mitogen-activated protein kinase.

\section{Discussion}

Our previous study revealed that LPS can upregulate the expression of Toll-like receptor 4 (TLR4), myeloid differentiation protein 2 (MD-2), TNF- $\alpha$, IL-6 and IL-1 $\beta$ in the rat alveolar macrophage cell line NR8383 $(29,30)$ because IL-1 $\beta$ is mainly released from activated macrophages (31) and is a downstream cytokine of activation of inflammasome and pyroptosis (28). Therefore, it was hypothesized that LPS may induce release of IL-1 $\beta$ through macrophage pyroptosis, which is partially responsible for the uncontrolled lung inflammation in ALI/ARDS. To address this issue, in the present study, the effects of LPS on macrophage pyroptosis and lung inflammation was investigated in vitro and in vivo. The in vivo results indicated that LPS i.t. treatment significantly increased excessive lung inflammation and neutrophil infiltration, in association with increased caspase- 1 cleavage and active IL-1 $\beta$ release. A similar result was also observed in RAW264.7 and NR8383 macrophage cell lines, in which NLRP3 and cleaved caspase-1 were upregulated and colocalized within the intracellular NLRP3 inflammasome following LPS treatment. Thus, LPS not only induced excessive lung inflammation through increasing macrophage and neutrophil recruitment but also caused a pyroptosis-biased macrophage death and subsequent IL-1 $\beta$ release.

The p38 MAPK signaling pathway has been suggested to be involved in the inflammatory response of ALI/ARDS $(20,21)$. The production of many cytokines, including IL- $1 \beta$, TNF- $\alpha$ and IL-6, which serve a key role in ALI/ARDS is mainly via the p38 MPAK signaling pathway (32). A number of anti-inflammatory medications work by targeting p38 MAPK $(33,34)$. Inhibition of p38 MAPK downregulated the IL-1 $\beta$ and reduced acute injury in intestinal ischemia reperfusion rats (35). In addition, blocking p38 downregulated the apoptosis of endothelia or epithelial cells producing protective effects on pulmonary alveolar-capillary barrier permeability (36-38). However, the exact mechanism of the p38 MAPK signaling pathway in inflammatory response and regulation remains to be elucidated. There are relatively few studies on the regulation of p38 MAPK for NLRP3 inflammasome and alveolar macrophage pyroptosis in the ALI/ARDS. In a recent study, NLRP3 gene knockout blocked NF- $\mathrm{KB}$ and the MAPK signaling pathway in a chronic unpredictable mild stress-induced depression mouse model (39). The results in the present study indicated 

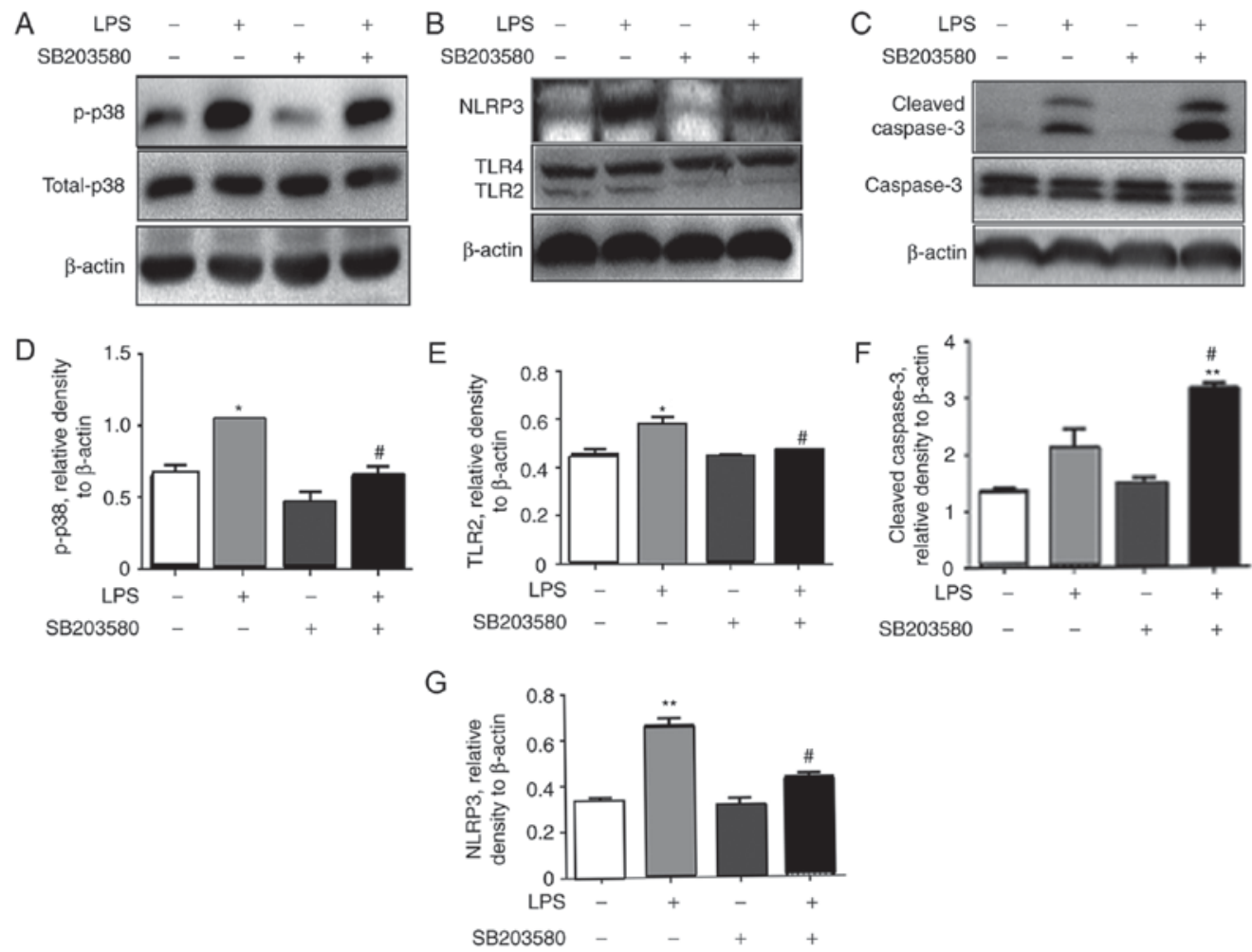

Figure 6. p38 MAPK inhibitor SB203580 suppresses the expression of NLRP3 and cleavage of caspase-1 in vitro. The rat macrophage cell line NR8383 was treated with $1 \mu \mathrm{g} / \mathrm{ml}$ LPS for $4 \mathrm{~h}$ with/without pretreatment with $10 \mu \mathrm{M}$ SB203580. Protein expression levels of (A) p-p38, (B) NLRP3 and TLR2/TLR4 and (C) caspase-3 and cleaved-caspase-3, were analyzed by western blot analysis. Quantitative analysis for (D) p-p38, (E) TLR2, (F) cleaved-caspase-3 and (G) NLRP3 was performed, and data are presented as the mean \pm standard error of the mean. ${ }^{*} \mathrm{P}<0.05,{ }^{* *} \mathrm{P}<0.01$ vs. the untreated control. ${ }^{\#} \mathrm{P}<0.05$ vs. the LPS treated group. $\mathrm{n}=3$ per sample. LPS, lipopolysaccharide; MAPK, mitogen-activated protein kinase; NLRP, nucleotide-binding domain, leucine-rich-containing family, pyrin domain-containing; p, phosphorylated; TLR, Toll-like receptor.

A
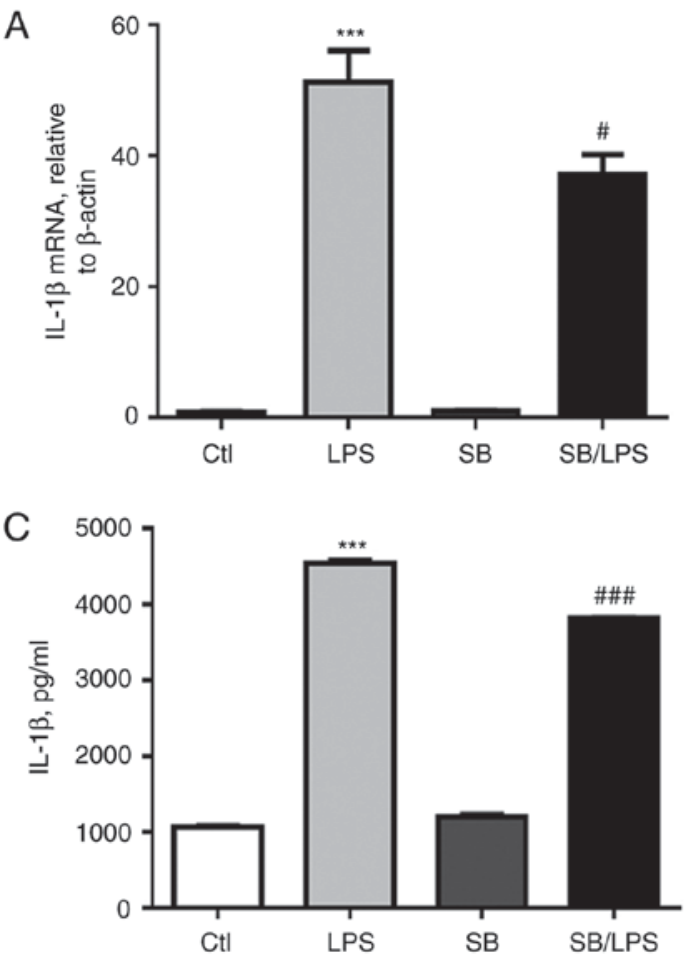

B
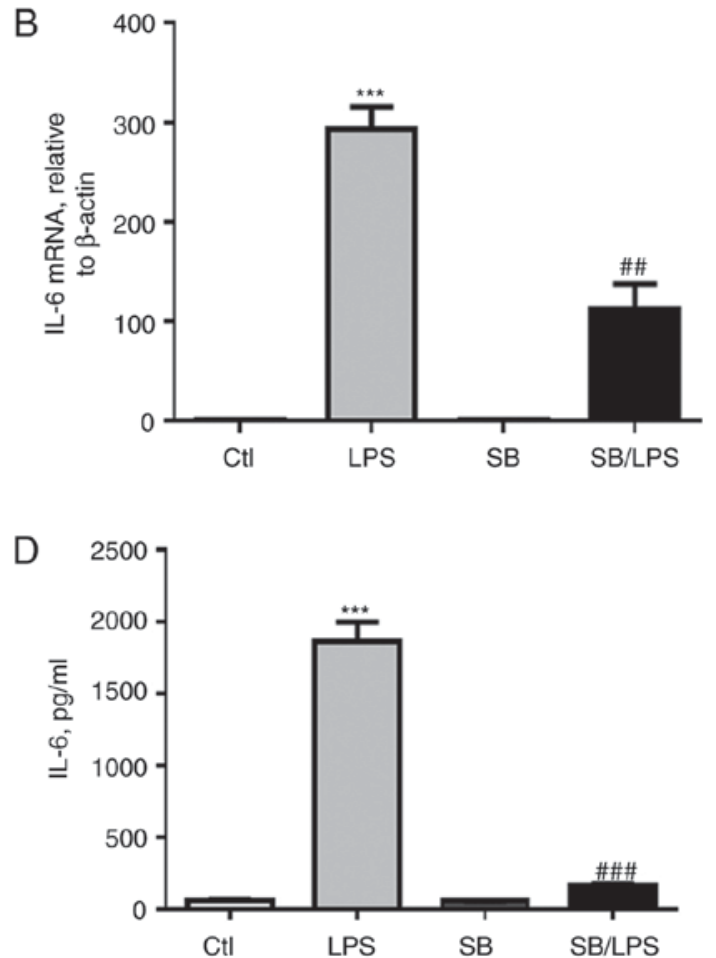

Figure 7. p38 MAPK inhibitor SB203580 suppresses the expression of IL-1 $\beta$ and IL-6 in the LPS-treated macrophages. The rat macrophage cell line NR8383 was treated with $1 \mu \mathrm{g} / \mathrm{ml}$ LPS for $4 \mathrm{~h}$ with/without pretreatment with $10 \mu \mathrm{M}$ SB203580. The mRNA expression levels of (A) IL-1 $\beta$ and (B) IL-6 in the treated cells were measured by RT-qPCR. The protein expression levels of (C) IL-1 $\beta$ and (D) IL-6 in the cell supernatants were measured by ELISA. Data are presented as the mean \pm standard error of the mean, $\mathrm{n}=3$ per group. ${ }^{* * *} \mathrm{P}<0.001$ vs. the untreated control group; ${ }^{\#} \mathrm{P}<0.05,{ }^{\# \#} \mathrm{P}<0.01$ and ${ }^{\# \# \#} \mathrm{P}<0.001$ vs. the LPS-treated group, $n=3$ per group. IL, interleukin; LPS, lipopolysaccharide; MAPK, mitogen-activated protein kinase. 
that LPS treatment activated NLRP3 and IL-1 $\beta$ expression and activation through the p38 MAPK signaling pathway because blocking the p38 MAPK signaling pathway through SB203580 pretreatment reversed the LPS-induced upregulation of TLR2, NLRP3, caspase-1, IL-1 $\beta$ and IL-6 in NR8383 cells. The suppressed p38 MAPK signaling pathway was associated with less caspase-1+PI+ pyroptotic cell population as analyzed by flow cytometry.

Thus, the blockage of p38 MAPK signaling pathway has the potential to suppress excessive lung inflammation by inhibiting inflammatory macrophage pyroptosis-biased cell death. This finding may encourage further studies of the beneficial role of p38 MAPK signal blockade in inhibiting uncontrolled lung inflammation in the ALI/ARDS animal model. I.p. pretreatment with SB203580 significantly suppressed acute lung injury, which was characterized by reduced alveolar edema, hemorrhage, alveolar septal thickening and infiltration of polymorphonuclear leukocytes compared with the mice that received LPS treatment alone. Consistent with the pathological observation, NLRP3 and TLR2 expression and caspase-1 cleavage in lung tissue were significantly reduced following SB203580 pretreatment. In addition, IL-1 $\beta$, TNF- $\alpha$ and IL-6 expression levels were attenuated, supporting the role of p38 MAPK signaling in LPS-induced acute lung injury and excessive lung inflammation. Previous studies indicated that TLR2/TLR3/TLR4/NF- $\mathrm{B}$ signaling pathway was involved in NLRP3 inflammasome activation in LPS-induced macrophages $(40,41)$. However, notable decreases in TLR4 expression levels was not evident, suggesting the possibility of reduced involvement of the TLR4/NF- $\kappa \mathrm{B}$ signaling pathway in p38 MAPK blockade.

It should be noted that greater cell apoptosis was observed following treatment with both LPS and p38 MAPK inhibitor compared with LPS treatment alone. The results were demonstrated by a larger Annexin V+PI- cell population and greater cleavage of pro-caspase-3 in the apoptotic cells treated with both p38 MAPK inhibitor and LPS. Apoptosis can prevent the leakage of pro-inflammatory mediator, proteases, reactive oxygen species production and lysozymes which contribute to promote and maintain self-tolerance and the resolution of lung inflammation $(42,43)$. Alveolar macrophages release the cytokines IL-8, TNF- $\alpha$ and IL-6 which not only directly induce lung injury but also recruit the neutrophils into the lung tissue as chemokines to aggravate the damage $(44,45)$. In contrast to the results in endothelial or epithelial cells (36-38), in macrophages it has been demonstrated that blocking the p38 MAPK signaling pathway enhances macrophage apoptosis and cleavage of caspase-3. The results suggested that inhibition of the p38 MAPK signaling pathway may promote a shift in macrophage cell death from proinflammatory pyroptosis towards a noninflammatory apoptosis process which may contribute to the attenuated acute lung injury and excessive inflammation in ALI/ARDS. However, it is important to maintain an optimal balance between pyroptosis and apoptosis during disease progression and this needs further research.

In conclusion, blocking the p38 MAPK signaling pathway may ameliorate acute lung injury and lung inflammation, partially through suppressing macrophage pyroptosis (Fig. 8). The results of the present study may provide a rationale for ALI/ARDS immunotherapy through modulation of p38 MAPK signaling pathway and macrophage pyroptosis.

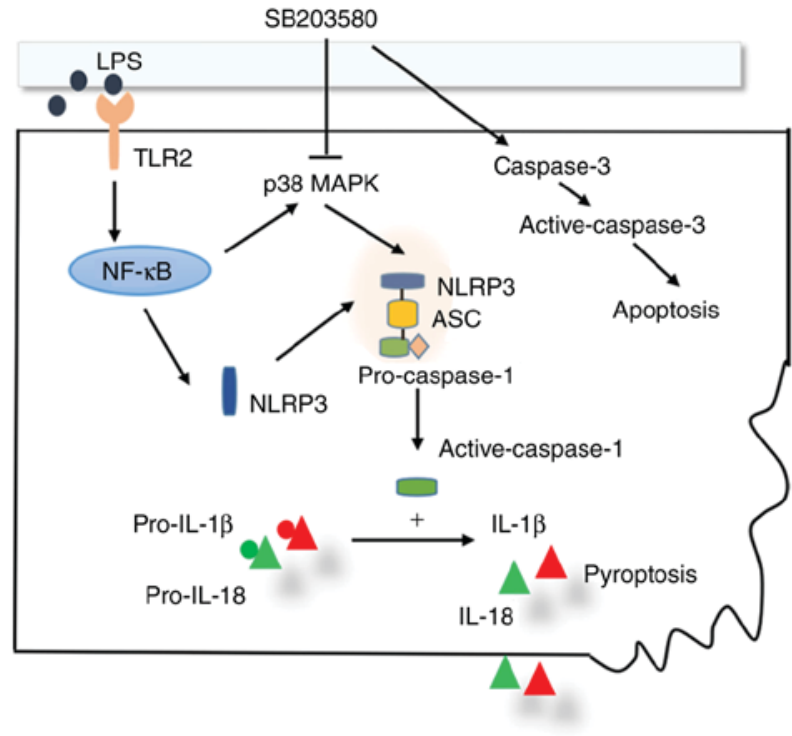

Figure 8. Schematic diagram of the p38 MAPK signaling pathway in the regulation of the NLRP3 inflammasome and macrophage pyroptosis. LPS activates p38 MAPK signaling pathway in macrophages through the TLR2/NF- $\kappa B$ signaling pathway, subsequently upregulating protein expression and promoting the formation of the NLRP3/caspase-1/ASC protein complex (NLRP3 inflammasome). The activated NLRP3 inflammasome cleaves pro-IL-1 $\beta$ and pro-IL-18 to become active IL-1 $\beta$ and IL-18, which ultimately induces macrophage pyroptosis. The signaling pathway is suppressed by $\mathrm{p} 38$ MAPK inhibitor SB203580. In addition, SB203580 upregulates caspase-3 and enhances macrophage apoptosis. ASC, apoptosis-associated speck-like protein; IL, interleukin; LPS, lipopolysaccharide; MAPK, Mitogen-Activated Protein Kinase; NF- $\kappa \mathrm{B}$, nuclear factor- $\kappa$-light-chain-enhancer of activated $\mathrm{B}$ cells; NLRP leucine-rich-containing family, pyrin domain-containing; TLR, Toll-like receptor.

\section{Acknowledgements}

The authors would like to thank the Experimental Center of Fudan University, Zhongshan Hospital (Shanghai, China) for their assistance and cooperation during the present study.

\section{Funding}

The present study was supported by a research grant from the National Natural Science Foundation of China and the Shanghai Three-Year Plan of the Key Subjects Construction in Public Health-Infectious Diseases and Pathogenic Microorganism to LZ (grant nos. 81270137 and 81300054) and support from Zhongshan Hospital, Fudan University in China to ZJ (grant no. A654116001).

\section{Availability of data and materials}

The datasets used and/or analyzed during the present study are available from the corresponding author on reasonable request.

\section{Authors' contributions}

DL performed the experiments, experimental design, data assembly, analysis and manuscript writing. ZJ participated in experimental design, data interpretation and manuscript writing. WR participated in the generation of ideas and data interpretation. LZ participated in the generation of the hypothesis and 
data interpretation and was responsible for the overall direction of the work. All authors read and approved the final manuscript.

\section{Ethics approval and consent to participate}

The experimental protocols were approved by the Laboratory Animal Care and Use Committee at the Medical College of Fudan University, Zhongshan Hospital (Shanghai, China).

\section{Patient consent for publication}

Not applicable.

\section{Competing interests}

The authors declare that they have no competing interests.

\section{References}

1. ARDS Definition Task Force, Ranieri VM, Rubenfeld GD, Thompson BT, Ferguson ND, Caldwell E, Fan E, Camporota L and Slutsky AS: Acute respiratory distress syndrome: The Berlin Definition. JAMA 307: 2526-2533, 2012.

2. Rubenfeld GD, Caldwell E, Peabody E, Weaver J, Martin DP Neff M, Stern EJ and Hudson LD: Incidence and outcomes of acute lung injury. N Engl J Med 353: 1685-1693, 2005.

3. Zhang Z, Chen L and Ni H: The effectiveness of corticosteroids on mortality in patients with acute respiratory distress syndrome or acute lung injury: A secondary analysis. Sci Rep 5: 17654, 2015

4. Frank JA, Wray CM, McAuley DF, Schwendener R and Matthay MA: Alveolar macrophages contribute to alveolar barrier dysfunction in ventilator-induced lung injury. Am J Physiol Lung Cell Mol Physiol 291: L1191-L1198, 2006.

5. Aggarwal NR, King LS and D'Alessio FR: Diverse macrophage populations mediate acute lung inflammation and resolution. Am J Physiol Lung Cell Mol Physiol 306: L709-L725, 2014.

6. Machado-Aranda D, V Suresh M, Yu B, Dolgachev V, Hemmila MR and Raghavendran K: Alveolar macrophage depletion increases the severity of acute inflammation following nonlethal unilateral lung contusion in mice. J Trauma Acute Care Surg 76: 982-990, 2014.

7. Niesler U, Palmer A, Fröba JS, Braumüller ST, Zhou S, Gebhard F, Knöferl MW and Seitz DH: Role of alveolar macrophages in the regulation of local and systemic inflammation after lung contusion. J Trauma Acute Care Surg 76: 386-393, 2014.

8. D'Alessio FR, Craig JM, Singer BD, Files DC, Mock JR, Garibaldi BT, Fallica J, Tripathi A, Mandke P, Gans JH, et al: Enhanced resolution of experimental ARDS through IL-4-mediated lung macrophage reprogramming. Am J Physiol Lung Cell Mol Physiol 310: L733-L746, 2016.

9. Jiang Z, Zhou Q, Gu C, Li D and Zhu L: Depletion of circulating monocytes suppresses IL-17 and HMGB1 expression in mice with LPS-induced acute lung injury. Am J Physiol Lung Cell Mol Physiol 312: L231-L242, 2017.

10. Qiu Z,Hu J, Van den Steen PE and Opdenakker G: Targeting matrix metalloproteinases in acute inflammatory shock syndromes. Comb Chem High Throughput Screen 15: 555-570, 2012.

11. Gustot T: Multiple organ failure in sepsis: Prognosis and role of systemic inflammatory response. Curr Opin Crit Care 17: 153-159, 2011.

12. Kovarova M, Hesker PR, Jania L, Nguyen M, Snouwaert JN, Xiang Z, Lommatzsch SE, Huang MT, Ting JP and Koller BH: NLRP1-dependent pyroptosis leads to acute lung injury and morbidity in mice. J Immunol 189: 2006-2016, 2012.

13. Liang J, Jung Y, Tighe RM, Xie T, Liu N, Leonard M, Gunn MD, Jiang D and Noble PW: A macrophage subpopulation recruited by $\mathrm{CC}$ chemokine ligand-2 clears apoptotic cells in noninfectious lung injury. Am J Physiol Lung Cell Mol Physiol 302: L933-L940, 2012

14. Wang Q, Imamura R, Motani K, Kushiyama H, Nagata S and Suda T: Pyroptotic cells externalize eat-me and release find-me signals and are efficiently engulfed by macrophages. Int Immunol 25: 363-372, 2013.
15. Compan V, Martín-Sánchez F, Baroja-Mazo A, López-Castejón G, Gomez AI, Verkhratsky A, Brough D and Pelegrín P: Apoptosis-associated speck-like protein containing a CARD forms specks but does not activate caspase-1 in the absence of NLRP3 during macrophage swelling. J Immunol 194: 1261-1273, 2015.

16. Lamkanfi M, Sarkar A, Vande Walle L, Vitari AC, Amer AO, Wewers MD, Tracey KJ, Kanneganti TD and Dixit VM: Inflammasome-dependent release of the alarmin HMGB1 in endotoxemia. J Immunol 185: 4385-4392, 2010.

17. Kamo N, Ke B, Ghaffari AA, Shen XD, Busuttil RW, Cheng G and Kupiec-Weglinski JW: ASC/caspase-1/IL-1 $\beta$ signaling triggers inflammatory responses by promoting HMGB1 induction in liver ischemia/reperfusion injury. Hepatology 58: 351-362, 2013.

18. Allam R, Kumar SV, Darisipudi MN and Anders HJ: Extracellular histones in tissue injury and inflammation. J Mol Med (Berl) 92: 465-472, 2014.

19. Haggadone MD, Grailer JJ, Fattahi F, Zetoune FS and Ward PA: Bidirectional crosstalk between C5a receptors and the NLRP3 inflammasome in macrophages and monocytes. Mediators Inflamm 2016: 1340156, 2016.

20. Xiong LL, Tan Y, Ma HY, Dai P, Qin YX, Yang RA, Xu YY, Deng Z, Zhao W, Xia QJ, et al: Administration of SB239063, a potent p38 MAPK inhibitor, alleviates acute lung injury induced by intestinal ischemia reperfusion in rats associated with AQP4 downregulation. Int Immunopharmacol 38: 54-60, 2016.

21. Ma L, Zhao Y, Wang R, Chen T, Li W, Nan Y, Liu X and Jin F: 3,5,4'-Tri-O-acetylresveratrol attenuates lipopolysaccharide-induced acute respiratory distress syndrome via MAPK/SIRT1 pathway. Mediators Inflamm 2015: 143074, 2015.

22. Pearson G, Robinson F, Beers Gibson T, Xu BE, Karandikar M, Berman K and Cobb MH: Mitogen-activated protein (MAP) kinase pathways: Regulation and physiological functions. Endocr Rev 22: 153-183, 2001

23. Sui X, Kong N, Ye L, Han W, Zhou J, Zhang Q, He C and Pan H: p38 and JNK MAPK pathways control the balance of apoptosis and autophagy in response to chemotherapeutic agents. Cancer Lett 344: 174-179, 2014

24. McGuigan RM, Mullenix P, Norlund LL, Ward D, Walts M and Azarow K: Acute lung injury using oleic acid in the laboratory rat: Establishment of a working model and evidence against free radicals in the acute phase. Curr Surg 60: 412-417, 2003.

25. Livak KJ and Schmittgen TD: Analysis of relative gene expression data using real-time quantitative PCR and the 2(-Delta Delta C(T)) method. Methods 25: 402-408, 2001.

26. Geng Y, Ma Q, Liu YN, Peng N, Yuan FF, Li XG, Li M, Wu YS, Li BL, Song WB, et al: Heatstroke induces liver injury via IL-1 $\beta$ and HMGB1-induced pyroptosis. J Hepatol 63: 622-633, 2015.

27. Galluzzi L, Vitale I, Abrams JM, Alnemri ES, Baehrecke EH, Blagosklonny MV, Dawson TM, Dawson VL, El-Deiry WS, Fulda S, et al: Molecular definitions of cell death subroutines: Recommendations of the nomenclature committee on cell death 2012. Cell Death Differ 19: 107-120, 2012.

28. Lamkanfi M and Dixit VM: Mechanisms and functions of inflammasomes. Cell 157: 1013-1022, 2014.

29. Ren WY, Zhu L, Hua F, Jin JJ and Cai YY: The effect of lipopolysaccharide on gene expression of TLR4 and MD-2 in rat alveolar macrophage and its secretion of inflammation cytokines. Zhonghua Jie He He Hu Xi Za Zhi 33: 367-371, 2010 (In Chinese).

30. Ren W, Hu L, Hua F, Jin J, Wang Y and Zhu L: Myeloid differentiation protein 2 silencing decreases LPS-induced cytokine production and TLR4/MyD88 pathway activity in alveolar macrophages. Immunol Lett 141: 94-101, 2011.

31. Netea MG, Simon A, van de Veerdonk F, Kullberg BJ, Van der Meer JW and Joosten LA: IL-1beta processing in host defense: Beyond the inflammasomes. PLoS Pathog 6: e1000661, 2010.

32. Bode JG, Ehlting C and Häussinger D: The macrophage response towards LPS and its control through the p38(MAPK)-STAT3 axis. Cell Signal 24: 1185-1194, 2012.

33. Liu W, Jiang HL, Cai LL, Yan M, Dong SJ and Mao B: Tanreqing injection attenuates lipopolysaccharide-induced airway inflammation through MAPK/NF- $\mathrm{BB}$ signaling pathways in rats model. Evid Based Complement Alternat Med 2016: 5292346, 2016.

34. Chen CC, Lin MW, Liang CJ and Wang SH: The anti-inflammatory effects and mechanisms of eupafolin in lipopolysaccharide-induced inflammatory responses in RAW264.7 macrophages. PLoS One 11: e0158662, 2016. 
35. Zheng DY, Zhou M, Jin J, He M, Wang Y, Du J, Xiao XY, Li PY, Ye AZ, Liu J and Wang TH: Inhibition of P38 MAPK downregulates the expression of IL-1 $\beta$ to protect lung from acute injury in intestinal ischemia reperfusion rats. Mediators Inflamm 2016: 9348037, 2016.

36. Bai X, Fan L, He T, Jia W, Yang L, Zhang J, Liu Y, Shi J, Su L and Hu D: SIRT1 protects rat lung tissue against severe burn-induced remote ALI by attenuating the apoptosis of PMVECs via p38 MAPK signaling. Sci Rep 5: 10277, 2015.

37. Wang Q, Wang J, Hu M, Yang Y, Guo L, Xu J, Lei C, Jiao Y and $\mathrm{Xu} \mathrm{J}$ : Uncoupling protein 2 increases susceptibility to lipopolysaccharide-induced acute lung injury in mice. Mediators Inflamm 2016: 9154230, 2016.

38. Xu X, Zhu Q, Niu F, Zhang R, Wang Y, Wang W, Sun D, Wang X and Wang A: A2BAR activation attenuates acute lung injury by inhibiting alveolar epithelial cell apoptosis both in vivo and in vitro. Am J Physiol Cell Physiol: Jun 13, 2018 (Epub ahead of print).

39. Su WJ, Zhang Y, Chen Y, Gong H, Lian YJ, Peng W, Liu YZ, Wang YX, You ZL, Feng SJ, et al: NLRP3 gene knockout blocks NF- $\mathrm{KB}$ and MAPK signaling pathway in CUMS-induced depression mouse model. Behav Brain Res 322: 1-8, 2017.

40. Xiang P, Chen T, Mou Y, Wu H, Xie P, Lu G, Gong X, Hu Q, Zhang Y and Ji H: NZ suppresses TLR4/NF- $\kappa \mathrm{B}$ signalings and NLRP3 inflammasome activation in LPS-induced RAW264.7 macrophages. Inflamm Res 64: 799-808, 2015.
41. Borges PV, Moret KH, Raghavendra NM, Maramaldo Costa TE, Monteiro AP, Carneiro AB, Pacheco P, Temerozo JR, Bou-Habib DC, das Graças Henriques $M$ and Penido C: Protective effect of gedunin on TLR-mediated inflammation by modulation of inflammasome activation and cytokine production: Evidence of a multitarget compound. Pharmacol Res 115: 65-77, 2017.

42. Robb CT, Regan KH, Dorward DA and Rossi AG: Key mechanisms governing resolution of lung inflammation. Semin Immunopathol 38: 425-428, 2016.

43. Linkermann A, Stockwell BR, Krautwald S and Anders HJ: Regulated cell death and inflammation: An auto-amplification loop causes organ failure. Nat Rev Immunol 14: 759-767, 2014.

44. Chollet-Martin S, Jourdain B, Gibert C, Elbim C, Chastre J and Gougerot-Pocidalo MA: Interactions between neutrophils and cytokines in blood and alveolar spaces during ARDS. Am J Respir Crit Care Med 154: 594-601, 1996.

45. Williams AE and Chambers RC: The mercurial nature of neutrophils: Still an enigma in ARDS? Am J Physiol Lung Cell Mol Physiol 306: L217-L230, 2014.

(i) $($ This work is licensed under a Creative Commons Attribution-NonCommercial-NoDerivatives 4.0 International (CC BY-NC-ND 4.0) License. 